Article

\title{
Application of Stochastic Dominance in Hedging Decision dur- ing COVID-19 Pneumonia Emergency Events
}

\author{
Wen Hsiang Chiu' ${ }^{1, *}$, Shih-Wei Hung ${ }^{2}$ \\ ${ }^{1}$ National Taiwan University of Science and Technology \\ 2 National Taipei University of Business \\ * Correspondence: wencheng@ntub.edu.tw; Tel.: 886-2-23226662
}

How to cite this paper: Chiu, W.H.; Huang, S.W. Application of Stochastic Dominance in Hedging Decision during COVID-19 Pneumonia Emergency Events. Universal Journal of Social Sciences and Humanities. 2021, 1(1), 11-17.

https://doi.org/10.31586/ujssh.2021.0 10102

Received: April 19, 2021

Accepted: May 25, 2021

Published: May 26, 2021

Copyright: () 2021 by the authors. Submitted for possible open access publication under the terms and conditions of the Creative Commons Attribution (CC BY) license (http://creativecommons.org/licenses /by/4.0/).

\begin{abstract}
With the rise of virtual currencies, Bitcoin has gradually become one of the safe-haven tools in the financial market. During situations of worldwide outbreaks of an infectious disease, investors pay special attention to asset allocation. Therefore, this study discusses the outbreak of COVID-19 in China, which has affected financial markets and has led investors to avoid risks through investing in traditional financial products or Bitcoin. We found that during the time of the COVID-19 pneumonia, Bitcoin and gold futures were used for hedging transactions in the face of unstable Chinese market conditions and under the pursuit of investors' maximization of return on investment. Furthermore, there was also no difference between hedging through Bitcoin or gold futures; however, investors had a preference to invest in gold futures for hedging under the assumption that an investor was absolutely risk averse.
\end{abstract}

Keywords: Gold Future; Bitcoin; COVID-19; Prospect Theory; Hedging Transactions.

\section{Introduction}

Among the rise of virtual currencies, Bitcoin has gradually become one of the safehaven tools in the financial market as well as a risk-averse tool for investors. Carrick [1] reported that Bitcoin is often included in exchange-traded funds in emerging markets, which tend to balance investment portfolios in terms of risk aversion. Dyhrberg [2] described Bitcoin as a currency as well as a commodity, functioning as a tool for hedging transactions (i.e., risk management). The use of Bitcoin as a hedging tool is particularly obvious in the Chinese market (Wang, Tang, Xie and Chen [3]. Indeed, an analysis of the economic value has shown that risk-averse investors are willing to pay a high-performance fee to switch from a portfolio with gold to a portfolio with Bitcoin (Henriques and Sadorsky [4].

Zhu et al. [5] used a vector error correction model to study the dynamic interaction between Bitcoin and important economic variables like the US dollar index, stock prices, the Federal Funds Rate, and gold prices. They found that although all variables have a long-term influence on Bitcoin prices, the US dollar index has the largest impact while gold prices have the least. The authors recommended that Bitcoin should be treated as a speculative asset rather than as a credit currency.

Detrended ratios were utilized by Baek and Elbeck [6] to examine relative volatility of Bitcoin and the S\&P 500 Index, and then modeled it by fundamental economic variables to study the volatility and return of the Bitcoin market. They discovered that the Bitcoin market was highly speculative at the time, was internally driven by buyers and sellers, and was not affected by fundamental economic variables.

Ciaian et al. [7] used the conceptual framework of the model by Barro (1979) with a time-series analytical mechanism to analyze the Bitcoin price formation by considering the traditional determinant of currency price and specific factors of digital currencies. 
They found that market forces and Bitcoin attractiveness significantly influence Bitcoin for investors and users.

In investors behavior theory, Kahneman and Tversky [8] proposed prospect theory based on observations in which investor behavior tends to be irrational and/or random in nature. The promise of profits encourages the collection of investment data; however, many investors follow sparse information or data that remain relevant only for a short period of time (Hirshleifer, Avanidhar and Sheridan [9]). Other investors tend to follow more reliable indicators to increase earnings or reduce losses (Hirshleifer and Luo, [10]). Many researchers have examined the impact of emergencies on the international movement of capital; however, investor sentiment and comparison of hedging effects of virtual currencies and traditional financial commodities have largely been overlooked.

Our objective in the current study was to consider the risk aversion factors of investors, explore the effect of hedging on different financial products, and fill relevant research gaps during emergency events associated with an infectious disease. Because investors pay special attention to the asset allocation during these times, this study discusses the outbreak of COVID-19 in China, which has affected financial markets and led investors to avoid risks, through investments in traditional financial products as well as Bitcoin. Under the psychological factors of investor risk aversion, we aimed to determine whether gold futures or Bitcoin was more suitable for risk aversion and had better hedging effects, by using the Cumulative Prospect Theory and stochastic dominance (CPT-SD). We also sought to identify the factors influencing investment behavior to provide a reference for governments and investors.

\section{Research Methods and Data Sampling}

Kahneman and Tversky [11] developed the weighting function of Cumulative Prospect Theory (CPT) on the basis of prospect theory and verified it with stochastic dominance (SD). The weighting function for the change of an investor's investment behavior in the face of an infectious disease is as follows (1):

$$
\mathrm{W}^{-}(\mathrm{P})=\frac{\mathrm{P}^{\delta}}{\left(\mathrm{P}^{\delta}+\left(1-\mathrm{P}^{\delta}\right)\right)^{\frac{1}{\delta}}} \quad \mathrm{W}^{+}(\mathrm{P})=\frac{\mathrm{P}^{\gamma}}{\left(\mathrm{P}^{\gamma}+\left(1-\mathrm{P}^{\gamma}\right)\right)^{\frac{1}{\gamma}}}
$$

where " $\mathrm{W} " \wedge(-)(" \mathrm{P} ")$ indicates the weight function of the return rate of investors less than $0, " \mathrm{~W} " \wedge(+)(" \mathrm{P} ")$ indicates the weight function of the return rate of investors exceeding 0 , and P refers to the probability of the return rate. Note that $\gamma$ and $\delta$ were respectively estimated at 0.61 and 0.69 by Kahneman and Tversky (1992).

Using weight function by CPT with first-order stochastic dominance (CPT-FSD), F ' $(\mathrm{P})>0$, which indicates that the return rate is proportional to the preference of investors, where $\mathrm{U}(\mathrm{R})$ is an investor's utility function for an investment return, as shown in equation (2):

$$
F(P) \leq G(P) \text {, for all possible } P
$$

$F(P)$ is the Bitcoin cumulative probability density function and $G(P)$ is the gold futures cumulative probability density function. Thus, for a given rate of return (at firstorder), the cumulative probability of $\mathrm{F}$ is smaller than that of $\mathrm{G}$; therefore, $\mathrm{F}$ is preferred to $\mathrm{G}$.

In addition to first-order stochastic dominance, we used second-order stochastic dominance (CPT-SSD) when considering risk aversion among investors. $\mathrm{U}^{\prime}(\mathrm{R})>0$ and $\mathrm{U}^{\prime \prime}$ $(\mathrm{R})<0$, indicating risk aversion by investors, as shown in equation (3): 


$$
\int F(P) \leq \int G(P) \text { for all possible } P
$$

Thus, for a given rate of return (at second-order), the cumulative probability of $\mathrm{F}$ is smaller than that of $G$; therefore, $F$ is preferred to $G$.

Finally, we used the third-order stochastic dominance (CPT-TSD) to discuss the case for the choice between Bitcoin and gold futures commodity. The attitude of investors in the face of risk is to absolutely avoid it. $U^{\prime}(R)>0$, U " $(R)<0$, and $U^{\prime \prime \prime}(R)>0$, which mean that investors get more investing compensation and that the amount of investment risk assets increases, as shown in equation (4):

$$
\iint F(P) \leq \iint \mathrm{G}(\mathrm{P}) \text {, for all possible } \mathrm{P}
$$

For a given rate of return (at third-order), the cumulative probability of $\mathrm{F}$ is smaller than that of $G$; therefore, $F$ is preferred to $G$.

\subsection{Data Sampling}

The series of Bitcoin prices were calculated as the mean of the highest daily price and the lowest daily price. Bitcoin price and gold futures data were collected from Investing.com, and Shanghai Composite Index (SSEI), Shenzhen Securities Component Index (SZSC) by Taiwan Economic Journal database (TEJ). The data used in this study consisted of daily observations on Bitcoin prices and the TEJ database. A total of 30 observations were included that covered the period from January 2nd to February 20th, 2020.

\section{Results}

We used the CPT with the SD method to estimate the subjective probability weight function of investors during the sample period. When the epidemic of COVID-19 broke out on January 23rd, 2020, both SSEI and SZSC declined significantly, as shown in Figure 1-2. Figure 3-4 indicates that while the price of Bitcoin and gold futures fell briefly during the outbreak, the quotations rebounded almost immediately. These findings demonstrate that when faced with the instability of the Chinese financial market, investors used Bitcoin and gold futures to hedge their transactions. Furthermore, this indicates that Bitcoin and gold futures are seen as important safe haven channels for investors in the face of emergencies associated with a worldwide outbreak of an infectious disease.

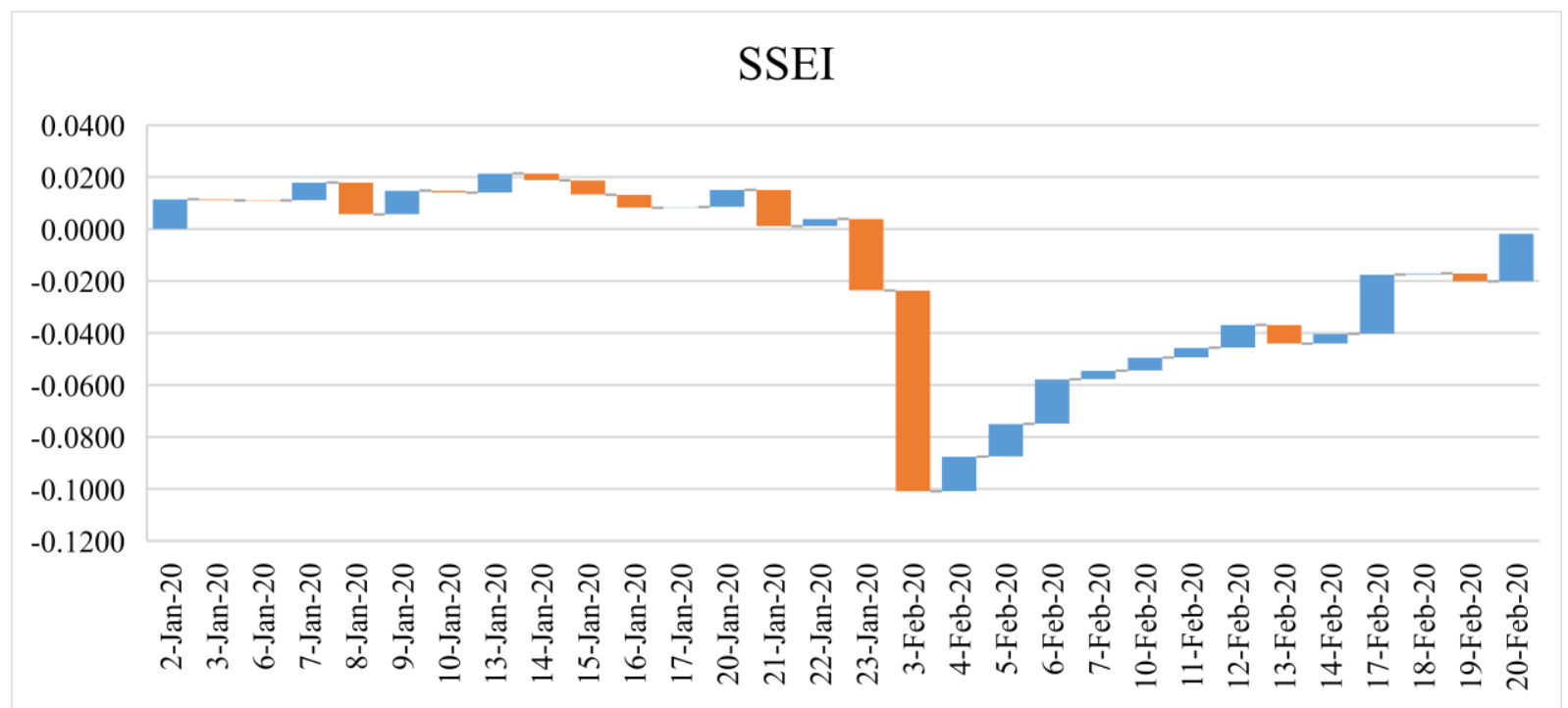

Figure 1. Shanghai Composite Index return (Jan 2nd to Feb 20th, 2020) 


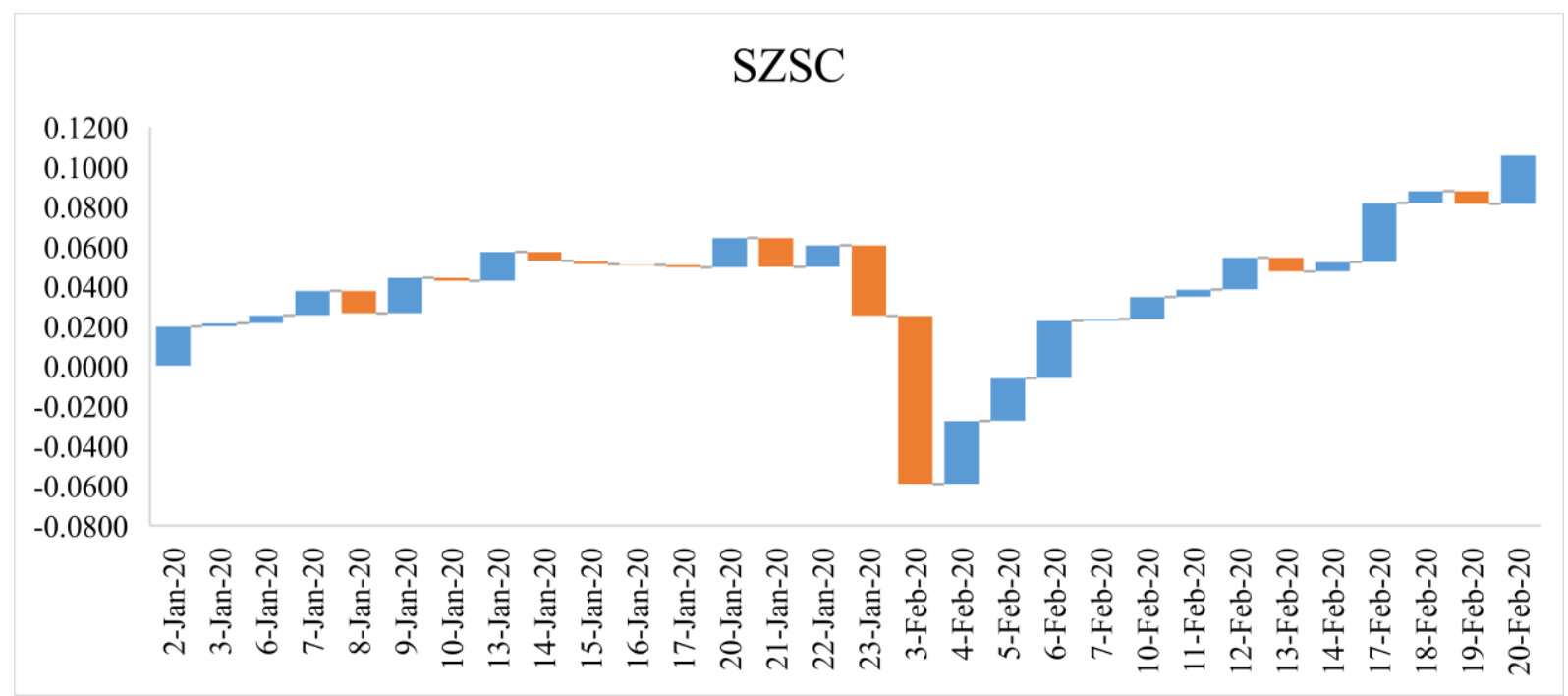

Figure 2. Shenzhen Composite Index return (Jan 2nd to Feb 20th, 2020)

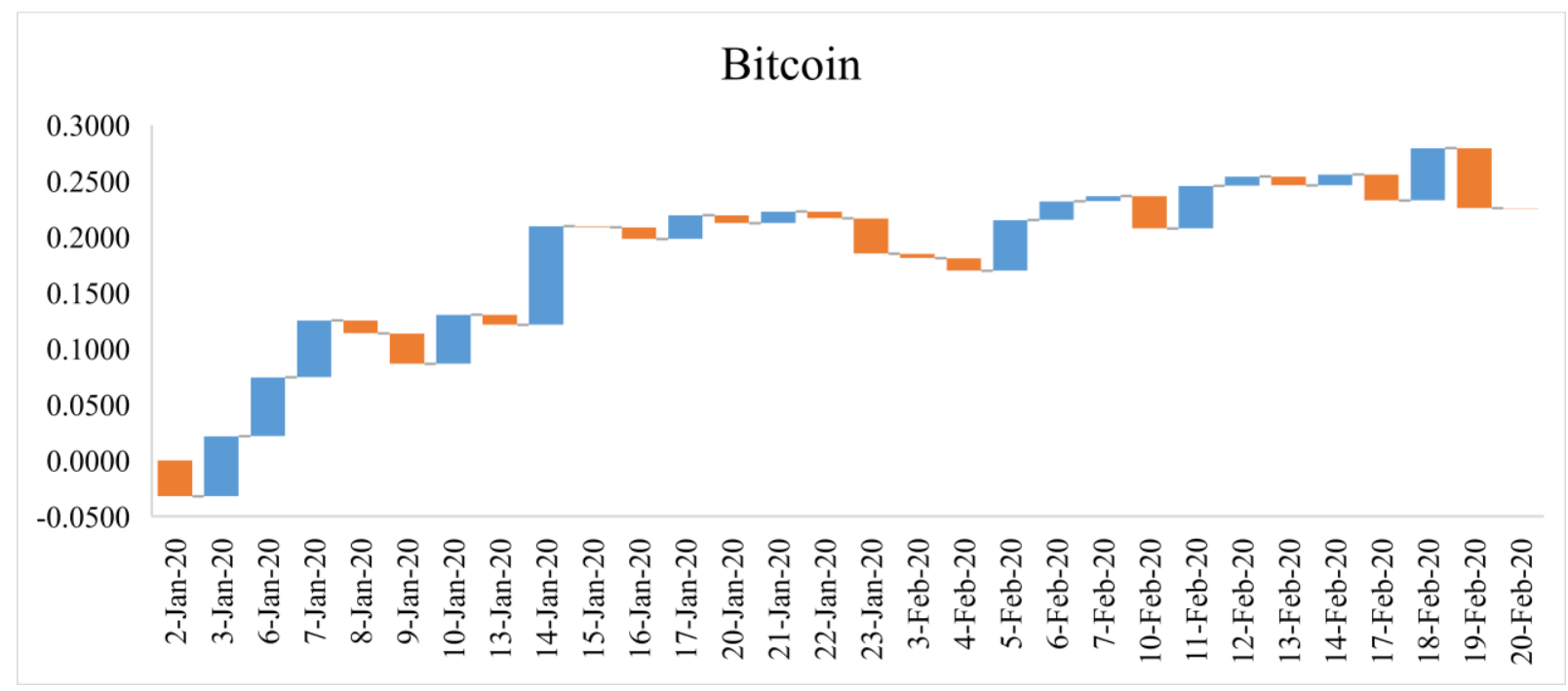

Figure 3. Bitcoin return (Jan 2nd to Feb 20th, 2020)

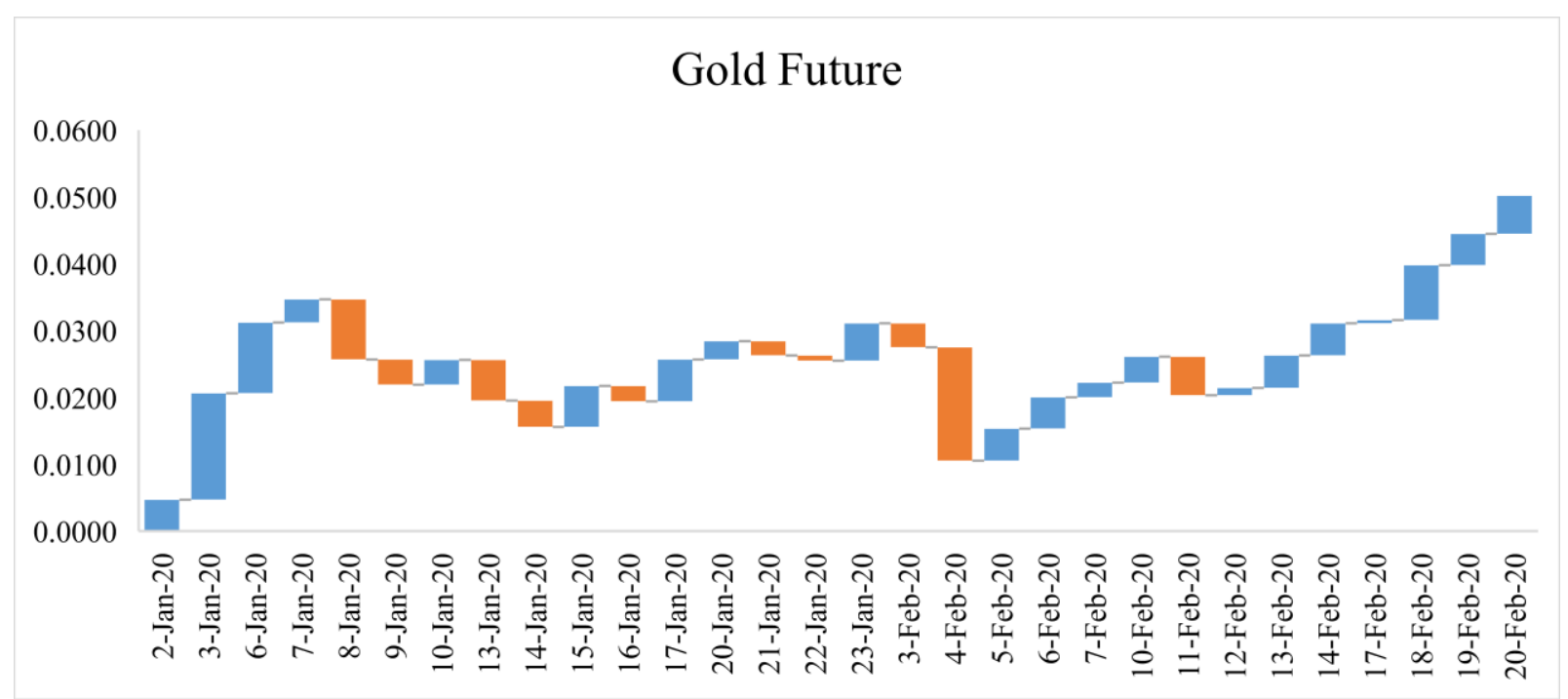

Figure 4. Gold futures return (Jan 2nd to Feb 20th, 2020) 
Stochastic dominance provides a simple tool for risk asset selection (Whitmore and Findlay) [12]. This study uses a simple example to explain the Stochastic Dominance relationship. If an investor wants to make a choice between two risky assets $X$ and $Y$, if the return of $X$ always exceeds the return of $Y$ in any future situation, if the investor is never satisfied, then the investor will not hold $Y$, because the return of holding $X$ is bound to be better.

In this study, we first need to know the type of reward rate value. Through the presentation of reward rate value, we can understand the investor's SSEI and SZSC hedging strategies, and thus affect the conversion and selection of subsequent probability weights of Gold Future and Bitcoin. To this end, we can observe how investors in the Chinese stock market used Gold Future and Bitcoin to take money out of the Chinese capital market during the outbreak of COVID-19.

In order to clarify whether investors prefer traditional financial products or virtual currencies for hedging in times of emergencies, this study used a first-order stochastic dominance under the assumption that the goal of an investor is to maximize the return on investment. As shown in Figure 5, there was no significant difference between Bitcoin and gold futures in terms of return on investment. For the second-order stochastic dominance analysis, investors were considered to have risk aversion, and as shown in Figure 6, the second-order cumulative probability density function in gold futures was significantly smaller than that of Bitcoin, suggesting that investors with risk aversion preferred to use gold futures for hedging. In terms of the third-order stochastic dominance, investors preferred gold futures to avoid investment risks in the case of absolute risk aversion, as shown in Figure 7.

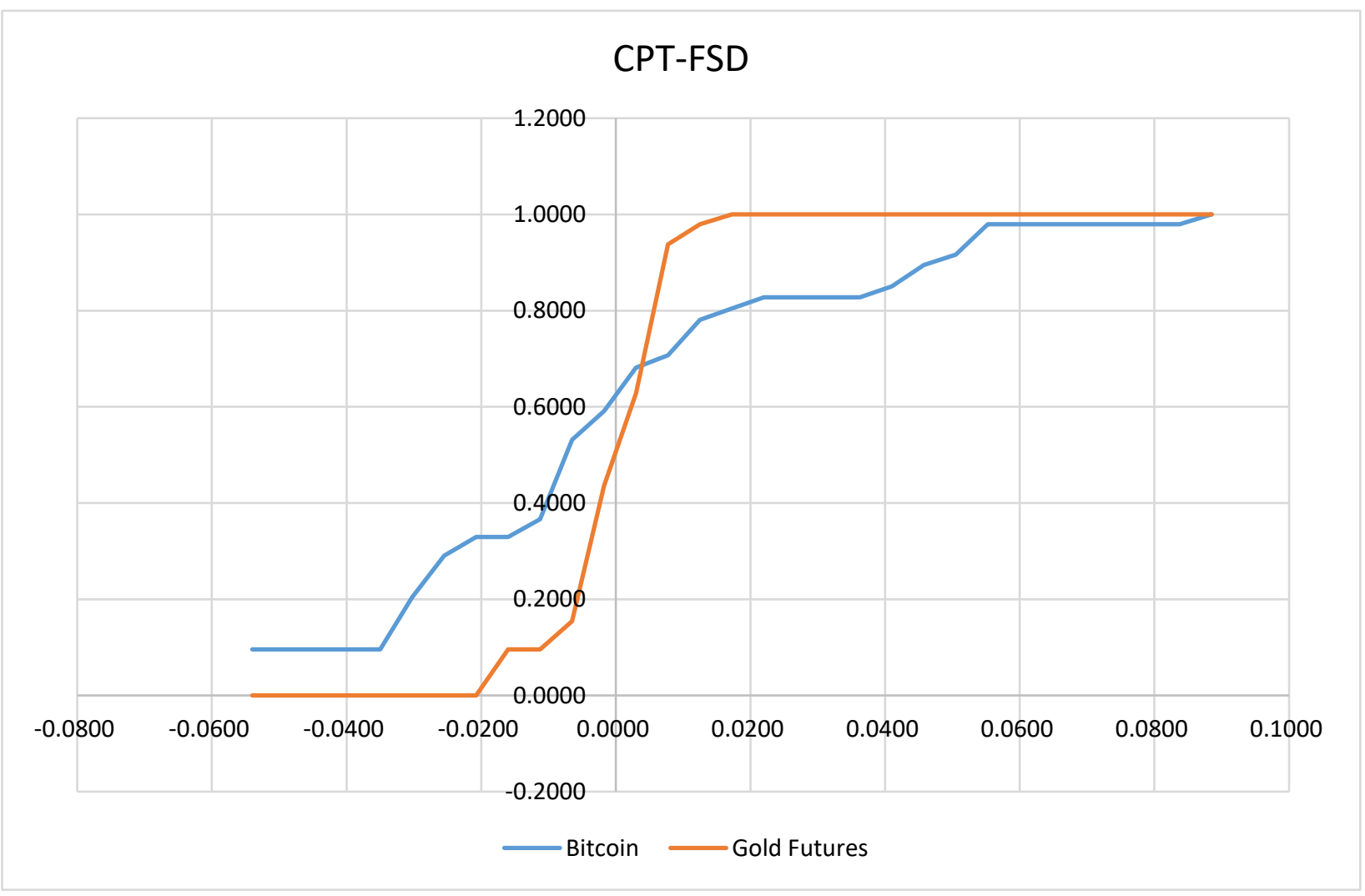

Figure 5. CPT-FSD for Bitcoin and Gold Futures 


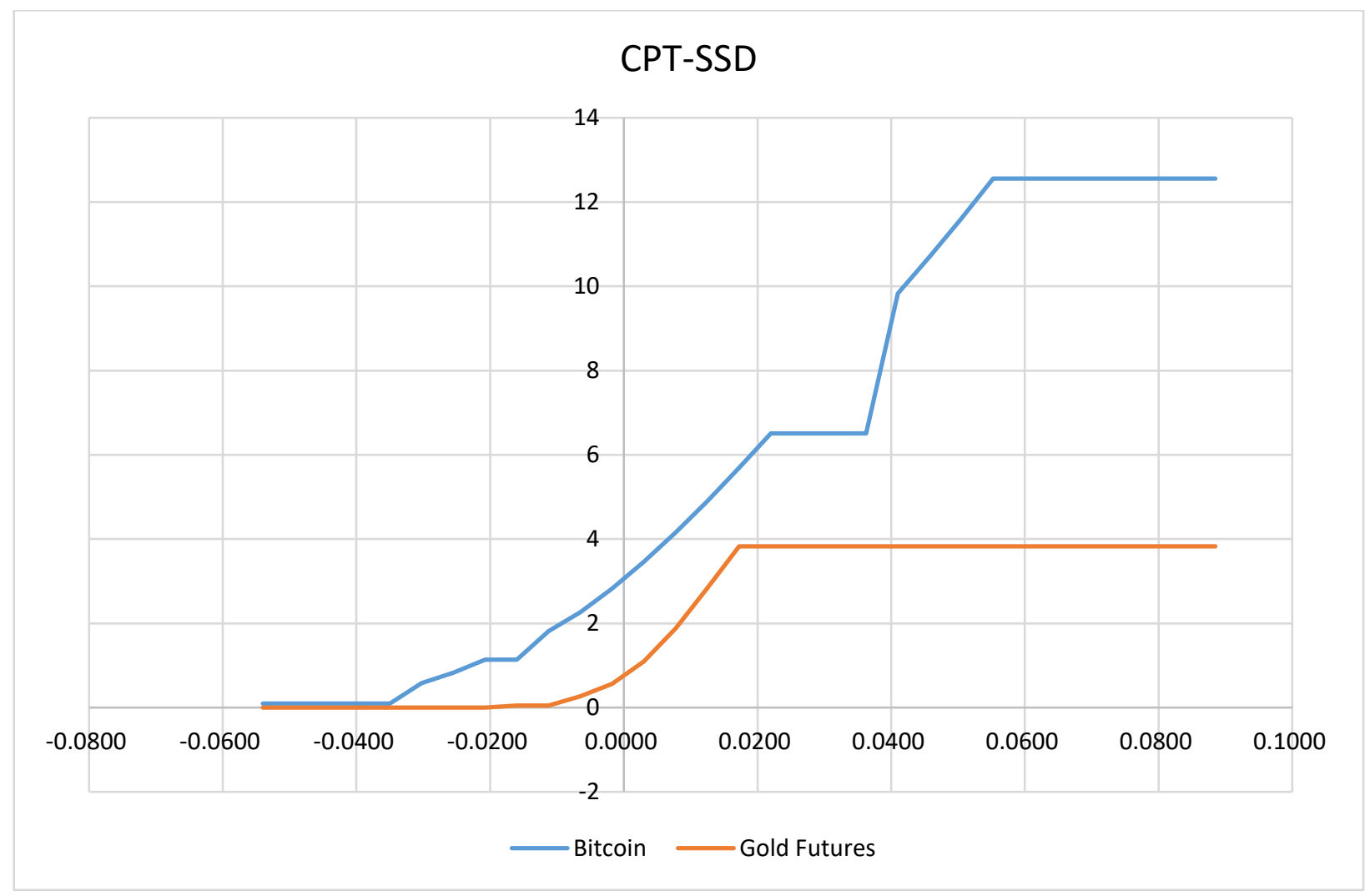

Figure 6. CPT-SSD for Bitcoin and Gold Futures

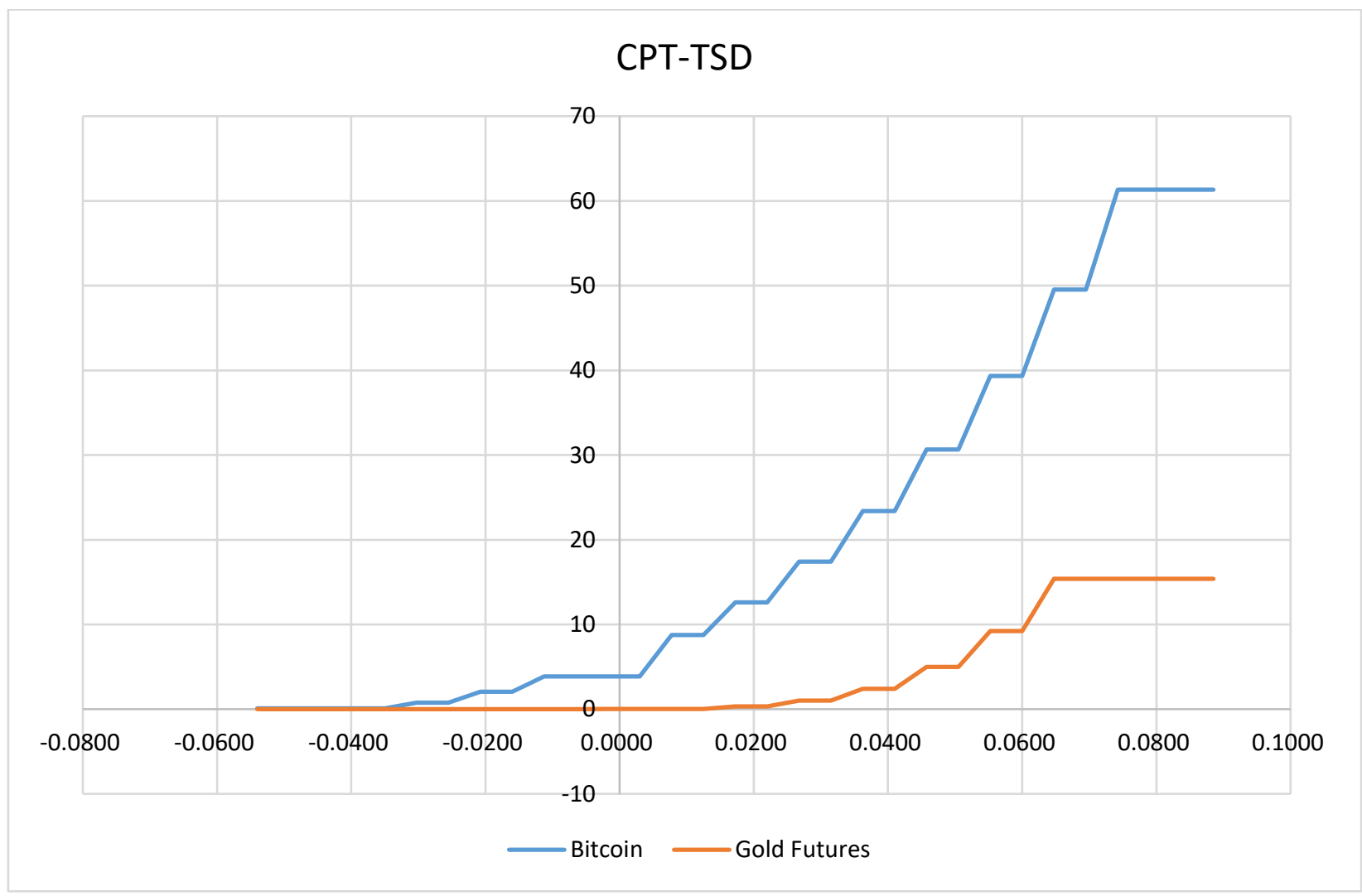

Figure 7. CPT-TSD for Bitcoin and Gold Futures 


\section{Conclusions and Policy implications}

Very few studies have discussed which traditional financial commodity or virtual currency is preferred by investors under a worldwide outbreak of an infectious disease. Therefore, this study used gold futures and Bitcoin to evaluate this through empirical methods of Cumulative Prospect Theory (CPT) with the stochastic dominance (SD) method. Following the outbreak of the Wuhan pneumonia in China in January 2020, the price of Bitcoin and gold futures rose, indicating that investors used Bitcoin and gold futures to avoid investment risks.

According to empirical results, at the time of the Wuhan pneumonia, the Chinese stock market fell sharply and investors panicked with respect to the Chinese capital market. During this time, Bitcoin and gold futures also fell, although briefly; however, the quotation rose almost immediately. In the face of unstable Chinese market conditions and under the pursuit of investors' maximization of return on investment, Bitcoin and gold futures were both used for hedging transactions. We found that there was no difference between hedging through Bitcoin or gold futures. Furthermore, when assuming that investors were absolutely risk averse, gold futures were the choice for hedging.

\section{References}

[1] Carrick, J. Bitcoin as a complement to emerging market currencies." Emerging markets finance \& trade. 2016. 52.10; pp. .23212334.

[2] Dyhrberg, A. H. Bitcoin, gold and the dollar-A GARCH volatility analysis. Finance Research Letters (2016).16; pp. 85-92.

[3] Wang, G., Y. Tang, C. Xie \& S. Chen. Is Bitcoin a Safe Haven or a Hedging Asset? Evidence from China. Journal of Management Science and Engineering. 2019. 4.3 ; pp. 173-188.

[4] Irene Henriques and Perry Sadorsky. Can Bitcoin Replace Gold in an Investment Portfolio? Journal of Risk and Financial Management. 2018.11, 48.

[5] Zhu, Yechen, David Dickinson, and Jianjun Li. Analysis on the Influence Factors of Bitcoin's Price Based on VEC Model. Financial Innovation. 2017..3: 3.

[6] Baek, C., \& M. Elbeck. Bitcoins as an investment or speculative vehicle? A first look. Applied Economics Letters. 2015. 22.1; pp. 30-34.

[7] Ciaian, P., M. Rajcaniova, \& D. A. Kancs. The economics of BitCoin price formation. Applied Economics. 2016.48.19; pp. 17991815.

[8] Kahneman, D. \& A. Tversky. Prospect Theory: An Analysis of Decision under Risk. Econometrica. 1979.47.2; pp. 263-291.

[9] Hirshleifer, D., S. Avanidhar, \& T. Sheridan. Security Analysis and Trading Patterns When Some Investor Receive Information Before Others. Journal of Finance. 1994..49.5; pp. 1665-1698.

[10] Hirshleifer, D. \& G. Y. Luo. On the Survival of Overconfident Traders in a Competitive Securities Market. Journal of Financial Markets. 2001. 4.1; pp. 73-84.

[11] Kahneman, D. \& A. Tversky. Advances in Prospect Theory: Cumulative Representation of Uncertainty. Journal of Risk and Uncertainty. 1992. 5.4; pp. 297-323.

[12] Whitmore, A. and Findlay, M.C. Stochastic Dominance. 1978. Lexington Books, New York. 